\title{
Undergraduate Thesis Reform of Accounting Major under the Transition Period of Shaanxi Private University
}

\author{
Wengang $X^{1} e^{1, a}$ \\ ${ }^{1}$ Xi'an International University, Xi'an, Shaanxi, 710077 \\ ${ }^{a}$ email
}

Keywords: Accounting Profession, Private Universities, Thesis, Reform

\begin{abstract}
Thesis to some extent reflects the strength of a professional school and undergraduate college teaching level. New Era, to achieve economies in transition into the new normal developments. Thus, senior personnel accounting classes increasingly needed by society. Accounting majors become hot, but also exposed some problems. In this paper, the status quo Accounting Graduation Thesis Quality of Private Universities in Shaanxi as the basis, to explore the impact factors of inadequate and proposed reform measures on this basis, around two aspects.
\end{abstract}

\section{Introduction}

Shaanxi Province is one of China's major education, the development of private colleges and universities are also at the forefront of the country. As of 2013, Shaanxi Province Private College students have 27.88 million, accounting for College Students in Shaanxi Province 27.2\%, higher than the national average. Where 53 private colleges and universities, private Universities 8 [1]. According to the "2016 China University Evaluation Study" survey data show that Xi'an Eurasia University in the National Financial Private University ranked in the fourth to give 5 star first class private university name. Xi'an International University, Xi'an Translation College Financial Management Major correspondingly get 4 stars, 3 stars in the world. Shaanxi undeniable Private University has made remarkable achievements, to meet the demand for more students to receive higher education for the society a large number of talents. However, with the arrival of the transitional period, the development of private colleges and universities in Shaanxi has entered the bottleneck of continued enrollment in public colleges and universities make admissions private colleges and universities has become difficult, the quality of students are declining.

Accounting majors include accounting profession and financial management professional. The content of the thesis is composed of professional education, is training students to think independently, rigorous attitude and important way to explore the application ability. Students also learn the theory of teaching and school achievement metrics [2]. Therefore, to discuss the reform of accounting thesis class, for improving the professional and private colleges and universities teaching quality of practical significance.

\section{Accounting Graduation Thesis Quality Status of Shaanxi Private Universities}

Quality Problem 1. theses on. Topic is the foundation step. Too broad essay topic should start on the existing research does not meet the level of refinement does not help too specific extension to express their views. For example, some entitled "The Discussion on the issue of the New Accounting Standards", "devaluation in the context of small and medium foreign enterprises coping strategies," "on corporate tax planning issues in research", "capital structure research", is a typical big and empty at the time of writing not start.

The quality of the paper on the retrieval. Students because of limited resources, they do not want to go voluminous library to find information, search only through the browser literature Baidu, Google on. The essence of a large number of papers and concentrate authority sites, such as underutilized HowNet, Wanfang Data, leading students to write papers lack of professionalism, not only the analysis of mechanical reproduction, the result in large areas of eastern and plagiarism West fight Minato situation. 
The quality of the writing on the paper. Writing papers and tissue is the main link. Since many schools do not have mentors in strict accordance with the rules and regulations to check the details of the students writing papers, leading students in the selection of references is not serious, a variety of flaws appear on expression and logically not rigorous, the directory is not clear. Even a casual fabricated data, apply the summary of the phenomenon [3]. For example, in writing "accounting error and accounting fraud manifestations comparative analysis" article, there is no field investigation and comparative analysis, but rather a case of copying an article, not knowing that this is the case a few years ago, "expressions" With the new definition. Still throughout typo wrong sentences, semantic unreasonable phenomenon also occur.

Quality Problems on paper format. Format biased, there are various non-compliant status. More common error is the "Summary" section can not be concise papers presented key points and the body portion, and the "introduction" of words, about the same content; and are usually at the beginning of the monotony, "With the rapid development of China's economy," "As people increasing living standards "and other such broad background information; in addition, footnotes, endnotes, references, labels and other undesirable canonical format, more English abstracts generated automatically by translation software on your computer and other issues.

Thesis did not put in place. This is the thesis writing "wrap up" session, the students receive college and teacher testing time. However, many institutions did not develop a complete score, the lack of scoring judge rationalization proposals, unfair and targeted. Students before the formal reply, there is no effective tutor guidance, to ensure timely completion of subject, there is no strict revision process. Reply often just a formality, a mere formality.

The paper guide does not effectively implemented. According to statistics, the number of private universities in Shaanxi accounting class students are more, less professional teacher force, a teacher guide students even dozen. And private colleges and universities to accept a variety of assessments, will focus more on the pursuit of innovation and development, therefore, some instructors may wear many hats, not enough time to give careful guidance paper. Usually takes hire some expert or accounting classes with professional teachers of public schools to participate in the completion of guidance papers [4]. For example, a school graduate accounting professional certified public accountant may be assisted by the teacher to guide the direction of international accounting, this way, to guide the work of college because of the different directions of research mentor can not be effectively implemented; there mainly because the instructor did not really have enterprises experience financial aspects, not timely access to market information, leading to poor guidance.

Review of papers not strictly enforced. Without a perfect review mechanism. According to the general process, the whole thesis should be completed by the opening report, thesis writing, mid-term examination, re-check the paper, thesis, dissertation binding these parts. However, many private universities set up mechanism is not perfect due to the lack of specialized papers examining division, in particular, the lack of funds unable to pay regular "HowNet" re-check system, resulting in poor paper review results.

The paper time no reasonable arrangements. Writing paper scheduled time is generally from senior semester began, students at this time facing a busy graduation practice, the pressure of employment, the civil service exam examination preparation, as well as obtain various permits. Students everywhere at once, time constraints, coupled with the relative lack of the usual training of professional thesis writing, thesis writing naturally attend to, but also pay attention to up.

\section{The Reform Measures of Undergraduate Thesis on Transformation Period of Private Colleges}

First, attention should be paid in the usual course teaching students creative thinking, rigor, scientific research ability, professional level of culture. Therefore, the school may offer co-curricular subjects other than the base, including training, elective courses to expand their horizons; you can also add the usual exercise and test papers, writing papers accumulated basis. For example, it requires a national policy and current events students to complete two or three thousand words a thousand words thesis analyzes the company's financial operation strategies.

Second, schools should provide more updated and thesis references. Includes not only 
professional papers website, should also involve some work with the company's accounting cases related to the management, hot social issues, economic policy and other information resources. Fully open reading room, to give students an optional subject, and create a good atmosphere of academic research.

Finally, carry out related seminars on thesis writing, careful to explain. For example, carried out in Xi'an Financial Private Colleges 2015 session of the Thesis, Department of Economics and Management of the entire department instructor made a "thesis, what guidance," the lecture. For thesis topics, thesis writing the summary and key words, introduction, title, and other aspects of multi-level regulatory requirements to make a detailed presentation, combined with practical examples and error prone area analysis and reviews [5]. As for thesis topics, the principle of linking theory with practice, have some new ideas (applications) and within the professional scope; topics Requirements: combining familiar topics enterprise companies to solve practical problems as the main objective to be combined with classroom teachers and students in innovative projects and scientific research topics; writing papers require prominent argument, logical structure, careful, persuasive language and so on.

First, the establishment of the monitoring system thesis instructor. Including the selection of teachers, guidance details clear, instructor assessment and so on. For example, a Department of Accounting at the College for teachers arranged thesis advisor task, adhere to the "three-tier hierarchical gatekeeper" management mechanism: First, check with the instructor guiding thesis; defense team leader to ensure quality; to the finishing department audit an examination. At the same time, take on the mentor "Regulation and Supervision" and "incentives to promote" a combination approach to management. Develop standards, poor graduation thesis guidance teacher quality (evaluated according to a comprehensive quality brought all students), as appropriate, the implementation of "punishment", that is to gradually reduce the number of guidance papers, or even cancel its guidance qualifications; thesis guiding level level will be included in the accounting department of teacher performance assessment; instructor of outstanding paper, the results can be included in the title cut of the reference indicators.

Second, the establishment of a standardized management system thesis. The Dissertation Proposal time sufficiently in advance to junior next semester, relieve students of all aspects of pressure; to the students of the topic give correct and guidance, combined with the actual conduct feasibility studies; review the students open question candidates or mission statement, check the students of literature search cases, schedule, etc., and with the final score of the paper proportionally linked [6]; in reply link, students are required to conduct a comprehensive and elaborate subtlety generalization based on papers prepared courseware, arrange other professional instructor will be anonymous peer assessment, pay would be converted, scoring rules correspond exactly to quantify the judge.

Third, the establishment of an effective verification system thesis. College students on the one hand to strengthen the thesis progress tracking, but also regulatory guidance teachers work; on the other hand, the instructor should pay attention to mid-term examination, always grasp the situation of students writing papers.

Fourth, establish a good instructor training system. Accounting majors because of practical, so in order to make teachers more competent thesis guidance, the College can make accounting professional teachers regularly go to school cooperative enterprise accounting practice and training of two months, this can improve the guidance of teachers, but also It can be a good grasp of market trends.

\section{Conclusion}

Thesis for accounting graduates, it aims to train students to combine theoretical knowledge elaboration and solve problems with financial accounting and management-related, and then tap the scientific potential. Private College Thesis Accounting class should cultivate applied talents as the objectives, guidelines and innovative paper management system, in many ways tap their academic potential, improve the quality of paper, so as to lay the foundation for the training of more 
specialized accounting personnel.

\section{Acknowledgements}

Project: scientific research projects of SHA rest education department no 15JK2121.

\section{References}

[1] Zhang Lei. explore the Accounting Professional Practice Undergraduate Thesis Reform [J]. China Education Innovation Herald, 2011 (16): 216-216.

[2] Han Linjing. Applied Undergraduate Graduation Design Reform and Practice - A professional financial management as an example [J]. Xunkan Accounting, 2011 (9): 110-113.

[3] Wu Liyang, Liu Xiaoyu. accounting Bachelor Thesis Orientation and Quality Monitoring Study [J]. Guangdong Pui Ching College, 2014 (4): 94-98.

[4] Zhang Xingliang. Situation accounting undergraduate thesis, objectives and quality control [J]. Jiaxing University, 2012, 24 (1): 139-144.

[5] Xiao Dan.On Accounting Undergraduate Thesis urgent need to enhance the quality of Chaudun [J]. Business Accounting, 2013 (20): 123-124.

[6] Xia Rong, Guan Xu. Financial Management Undergraduate Thesis Quality Management - Based on the Analysis of Nanjing University Jinling Institute [J]. Foreign Trade, 2012 (5): 137-138. 